\title{
Effect of biologic agents on radiographic progression of rheumatoid arthritis
}

This article was published in the following Dove Press journal:

Reports in Medical Imaging

27 August 2010

Number of times this article has been viewed

\author{
Gabriel J Tobón' \\ Alain Saraux ${ }^{1,2}$ \\ Valérie Devauchelle- \\ Pensec ${ }^{1,2}$ \\ 'Immunology Laboratory, Morvan \\ Hospital, Université de Bretagne \\ Occidentale, Brest, France; \\ ${ }^{2}$ Rheumatology Unit, Hôpital de la \\ Cavale Blanche, $\mathrm{CHU}$ Brest, France
}

Correspondence: Valérie DevauchellePensec

Rheumatology Unit, Brest

University Medical School,

BP 824, F29609 Brest, France

$\mathrm{Tel}+33298347267$

Fax +33 298493627

Email valerie.devauchelle-pensec@

chu-brest.fr

\begin{abstract}
The treatment of rheumatoid arthritis (RA) has benefited over the last few years from the introduction of biologic agents whose development was based on new insights into the immunological factors involved in the pathogenesis of RA and the development of joint damage. These biological agents have been proven effective in RA patients with inadequate responses to synthetic disease-modifying antirheumatic drugs (DMARDs). Preventing joint damage is now the primary goal of RA treatment, and guidelines exist for the follow-up of joint abnormalities. Most biologic agents produced high clinical and radiological response rates in patients with established or recent-onset RA. Thus, for the first time, obtaining a remission is a reasonable treatment goal in RA patients. Factors that are crucial to joint damage control are: early initiation of DMARDs, use of intensive treatments including biological agents, and close monitoring of clinical disease activity and radiographic progression. However, some patients remain unresponsive to all available treatments and continue to experience joint damage progression. A major objective now is to identify patients at high risk for severe joint damage, in order to tailor the treatment regimen to their specific needs.
\end{abstract}

Keywords: rheumatoid arthritis, radiographic progression, biologics

\section{Introduction}

Rheumatoid arthritis (RA) is a chronic, immune-mediated, inflammatory disease with a prevalence of about $0.5 \%$ to $1 \% .{ }^{1}$ RA causes not only pain, but also progressive joint destruction that leads to functional impairments and quality-of-life alterations. ${ }^{2,3}$ Preventing joint damage is now the primary treatment objective in RA.

RA is a heterogeneous disease whose outcome is difficult to predict. Some patients never develop erosions, but most start experiencing rapidly progressive joint destruction and disability soon after disease onset. Several studies have showed that $70 \%$ of RA patients developed erosions within 3 years of disease onset and that the total radiographic score for joint destruction increased linearly over time. ${ }^{4,5}$ However, there is now evidence of an early window of opportunity during which treatment initiation improves outcomes. Synthetic disease-modifying antirheumatic drugs (DMARDs), most notably methotrexate, have consistently been found to improve the clinical status and to slow radiographic progression in patients with RA. Furthermore, in patients who fail to achieve an adequate response to synthetic DMARDs, biological agents can provide sustained disease control with prevention of further joint damage. ${ }^{6}$ Thus, for the first time in the history of RA, achieving a remission is a realistic treatment objective. Although a detailed definition of RA remission is not yet available, an 
essential criterion is complete absence of clinical or radiological evidence of synovitis, probably for a certain length of time.

The aim of this review is to discuss the effect of biologic therapy on radiographic disease progression in RA patients.

\section{Radiographic evaluation in rheumatoid arthritis How to monitor joint damage}

The reference standard method for assessing joint damage and treatment efficacy in RA patients is plain radiography, although ultrasound and magnetic resonance imaging (MRI) are under investigation. In clinical practice, three radiographs must be obtained, namely, anterior-posterior views of the hands and feet, and an oblique view of the feet, for the diagnosis, with anterior-posterior views of the hands and feet for the follow-up. ${ }^{7}$ In everyday practice, this set of plain radiographs should be obtained every 6 months when the treatment is being modified and once every two years when the treatment is stable (Figures 1-4).

\section{Radiograph scoring methods}

Several scores have been developed for measuring radiographic progression in RA. ${ }^{8,9}$ The most commonly used score for evaluating biologic therapy is the Sharp score modified by van der Heijde, ${ }^{10}$ although several other scores exist. In 1971, Sharp described a method for separately scoring erosions and joint space narrowing (JSN) at 27 sites of the hands and wrists. ${ }^{11}$ However, damage to the small joints of the feet is common in RA and may develop earlier than damage to the hands and wrists. ${ }^{12}$ Therefore, van der Heijde modified Sharp's score to include 16 areas for erosions and 15 for JSN at the hands, and six areas for erosions and six for JSN at the feet (Figure 5). The erosion score can range from 0 to 5 at the hands and from 0 to 10 at the feet. The total Sharp score (TSS) is obtained by summing the erosion and JSN scores (Figures 6 and 7).

Among other radiographic scores, the most widely used in studies of biologics is the score developed by Genant et al ${ }^{13}$ which served mainly to evaluate rituximab and anakinra in RA. At each site, erosions are scored on an 8-point scale with half-grades ( 0.5 point) indicated by the $+\operatorname{sign}(0$, normal; $0+$, questionable or subtle change; 1 , mild; $1+$, mild to moderate; 2 , moderate; $2+$, moderate to severe; 3 , severe; and 3+, most severe). On each hand, erosions are assessed at 14 sites (proximal interphalangeal joint of the thumb, metacarpalphalangeal joints, carpal-metacarpal joints, scaphoid, ulna, and radius). The erosion score at the hands is obtained by summing the scores at each site, so that the range is 0 to 98 . JSN is scored at 13 sites per hand on a 9-point scale, also using half-grades, from normal (0) to ankylosed or dislocated
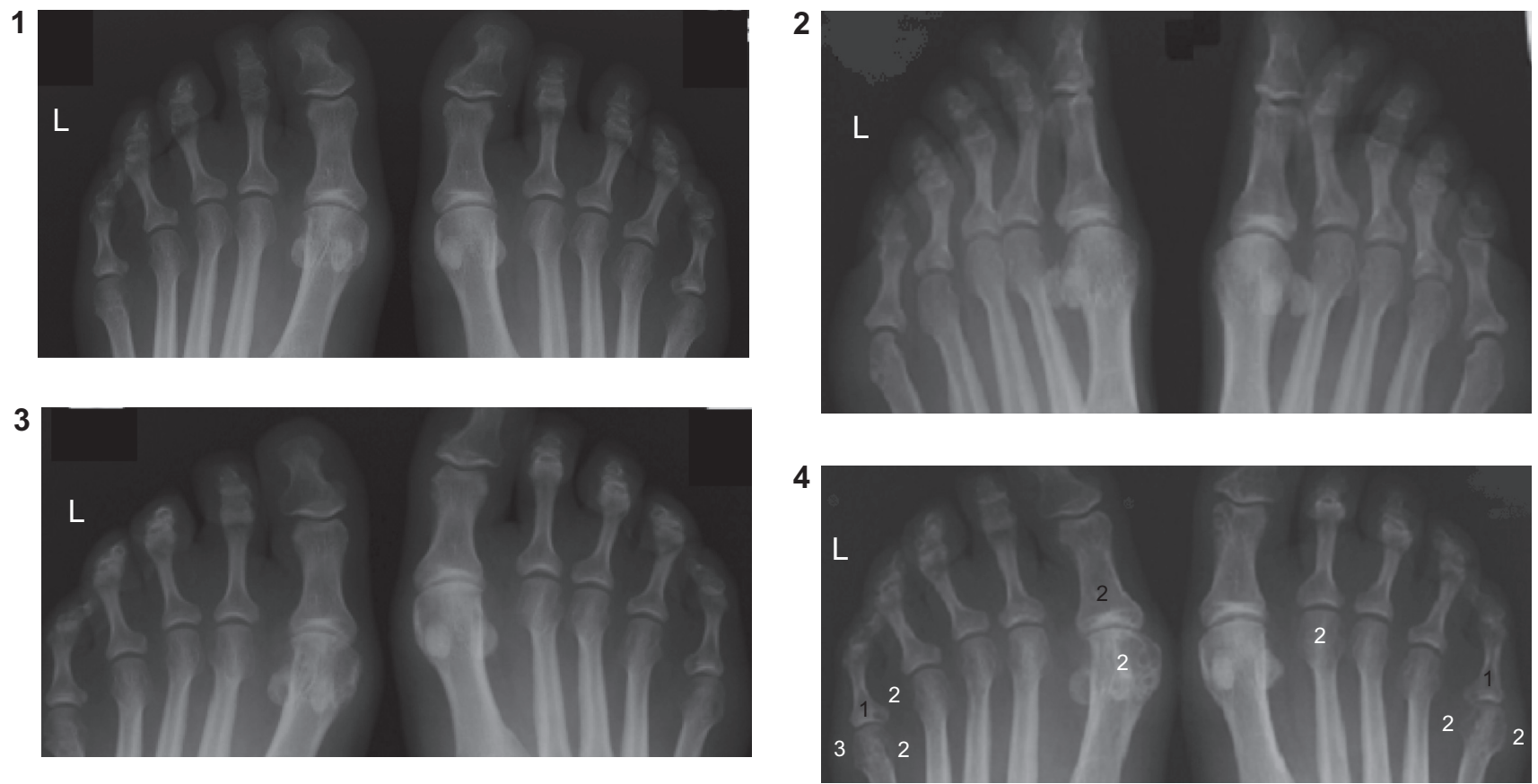

Figures I-4 Example of radiographic progression at the feet. Radiographs obtained every 6 months were evaluated using the Sharp/van der Heijde score. Joint space narrowing scores are shown in black and erosion scores in white. The anterior-posterior [I] and oblique [2] views of the feet at inclusion were considered normal. No progression was considered on AP [3] view at 6 months. Marked progression was noted after 12 months [4]. 


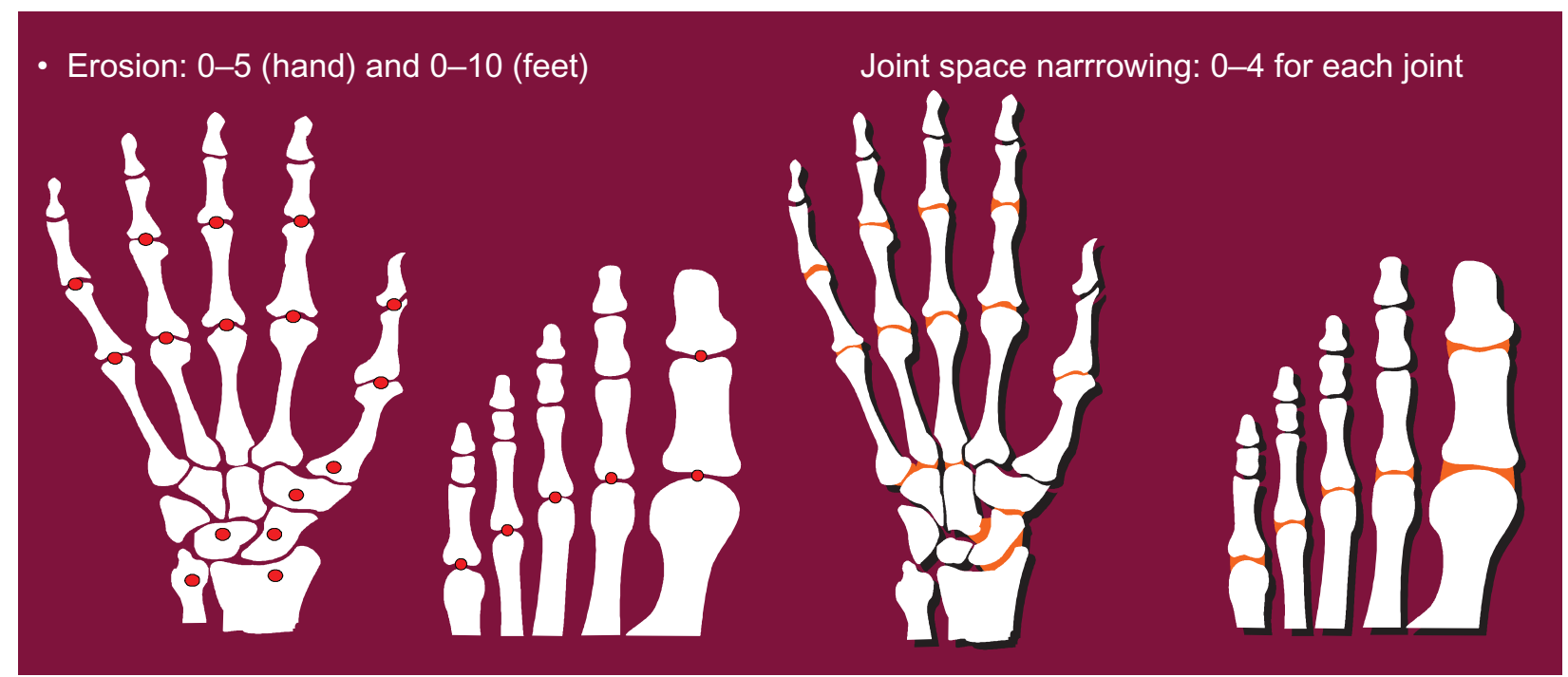

Figure 5 The Sharp/van der Heijde method for scoring radiographic damage at the hands and feet in patients with RA. Erosions are assessed in 16 areas of each hand and 6 of each foot. Joint space narrowing is assessed in 15 areas of each hand and 6 of each foot.

Erosions (hands)

$0=$ no erosion

$1=$ small erosion

2 = large erosion

$3=$ large erosion, passing the middle-line

Erosion score is the sum of the erosions with a maximum of 5 per joint
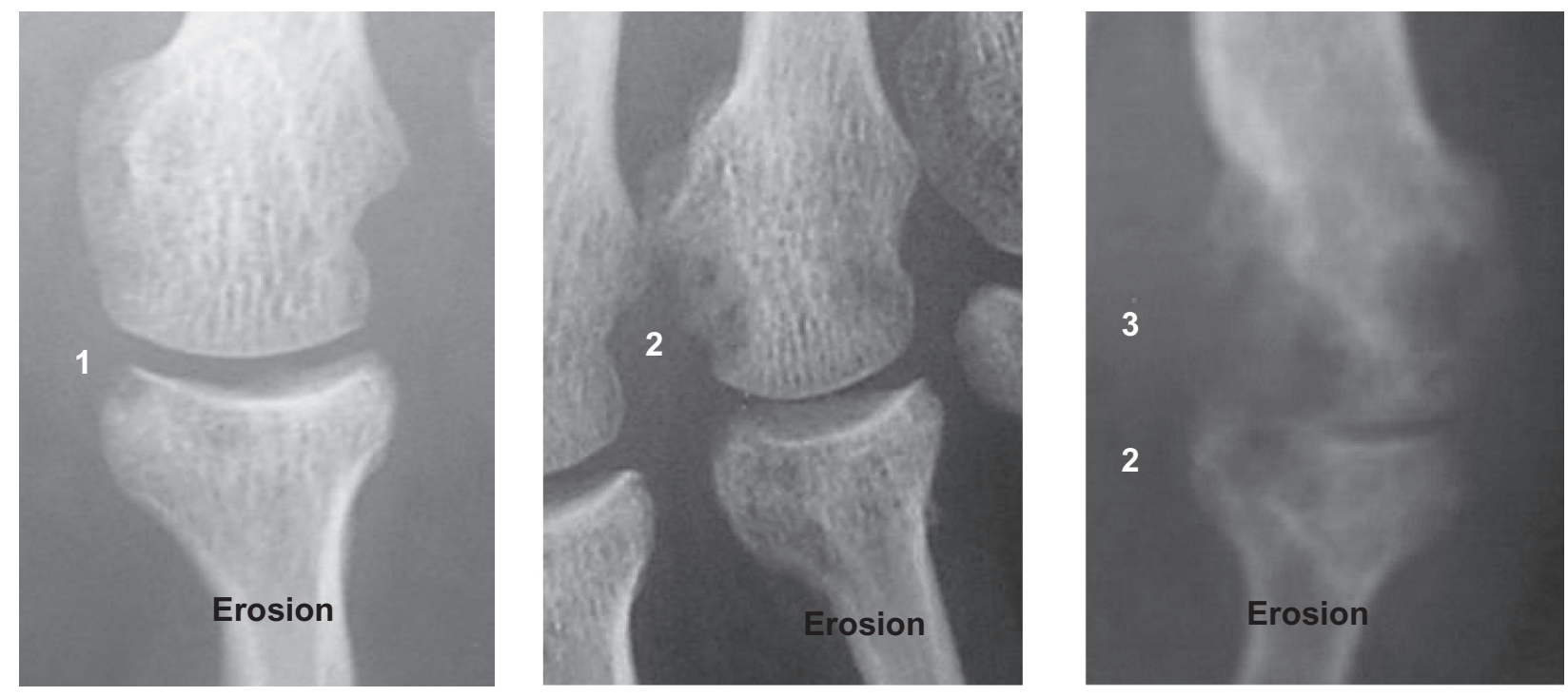

Figure 6 The Sharp/van der Heijde method for scoring erosions. The erosion score can range from 0 to 5 at the hand and from 0 to 10 at the feet. 


\section{Joint space narrowing}

$0=$ normal

$1=$ focal or minimal

2 = generalized, $>50 \%$ of joint space present

$3=$ generalized, $<50 \%$ of joint space present or subluxation

$4=$ no joint space left, ankylosis or luxation
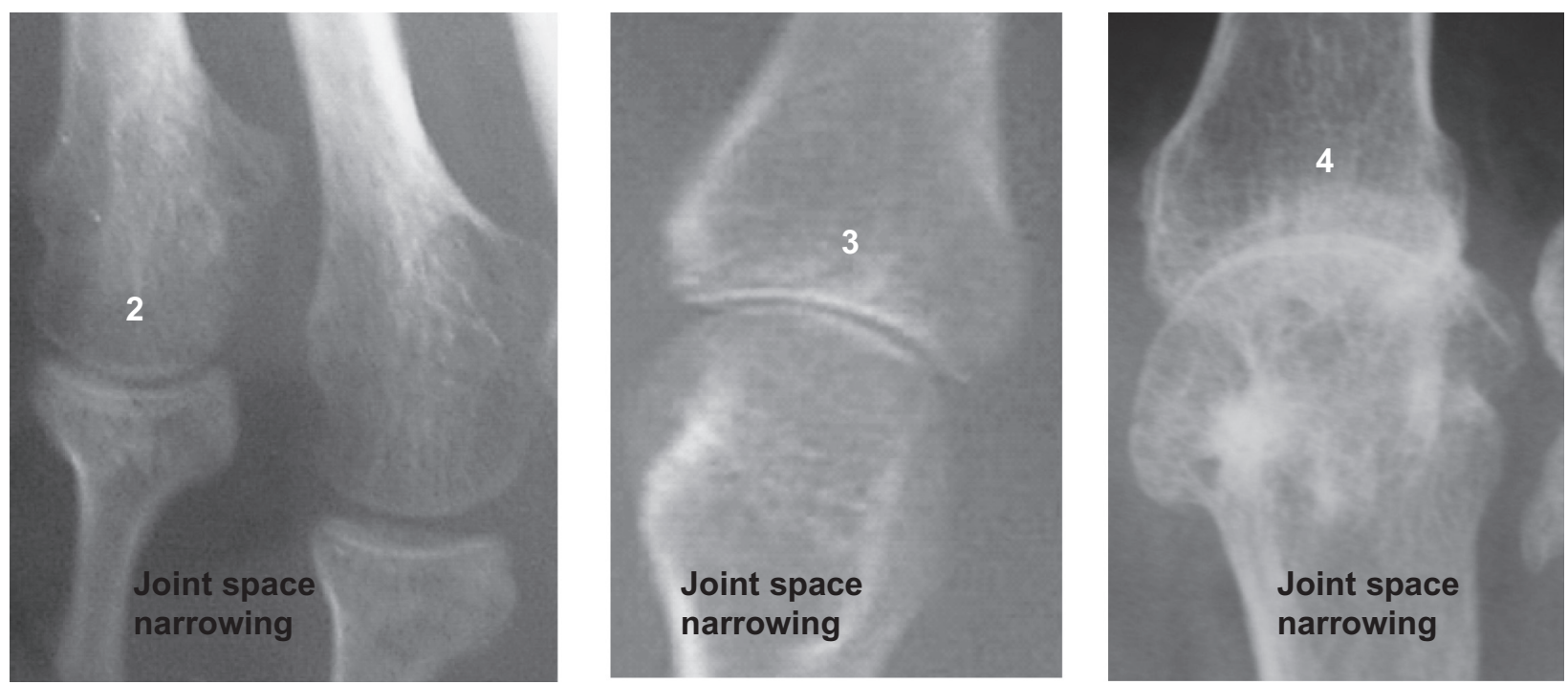

Figure 7 The Sharp/van der Heijde method for scoring joint space narrowing from 0 to 4 (with half-grades) at the hands and feet. The erosion and joint space narrowing score can be summed to obtain the total Sharp score (TSS).

(4, the most severe grade). The JSN score can range from 0 to 104 . Owing to the scoring system, the total Genant score is lower than the TSS.

In studies of biologics, obtaining annual radiographs of the hands and feet is usually sufficient to detect radiographic score changes. However, for specific research questions, in early RA, or in patients with factors predicting severe joint damage, radiographs must be obtained at closer intervals (Figures 8-10). In these situations, including larger numbers of joints and evaluating radiographs after 24 weeks may be appropriate. ${ }^{14,15}$

Good intraobserver and interobserver reproducibility is crucial if scores are to be useful for assessing changes over time. ${ }^{16}$ Most of the radiographic scores used in RA have been proven reproducible. The intraobserver and interobserver reproducibility of five radiographic scores were compared in 22 patients with RA. ${ }^{17}$ Reproducibility of the Larsen, Larsen/Rau, Sharp, Sharp/van der Heijde and simple erosion narrowing score was assessed at baseline and over a mean follow-up of 30 months using intraclass correlation coefficients (ICC) and Bland-Altman graphs. Intraobserver reproducibility varied across raters (ICC, 0.90-0.97) and was best with the Larsen and Larsen/Rau scores. Interobserver reproducibility was best with the Sharp and Sharp/van der Heijde scores (ICC, 0.76-0.93). Agreement as assessed using Bland-Altman graphs decreased with greater joint damage severity. Sensitivity to change was also assessed in this study and was best with the Sharp and Sharp/van der Heijde scores.

\section{Radiographic progression in rheumatoid arthritis \\ Natural history}

Several studies in early RA have shown that $70 \%$ of patients develop erosions within 3 years of RA onset. Furthermore, the total radiographic score increases linearly over time, but the increase is more rapid over the first 2 years and most of the damage occurs within the first 5 years. ${ }^{3,4}$ Annual score increases ranged across studies from 1.9 to 5.4 for erosions, 2.6 to 3.2 for JSN scores, and 4.5 to 8.6 for total scores. ${ }^{3,4}$ In the ESPOIR cohort ${ }^{18}$ of patients with recent-onset RA (mean disease duration at baseline, 

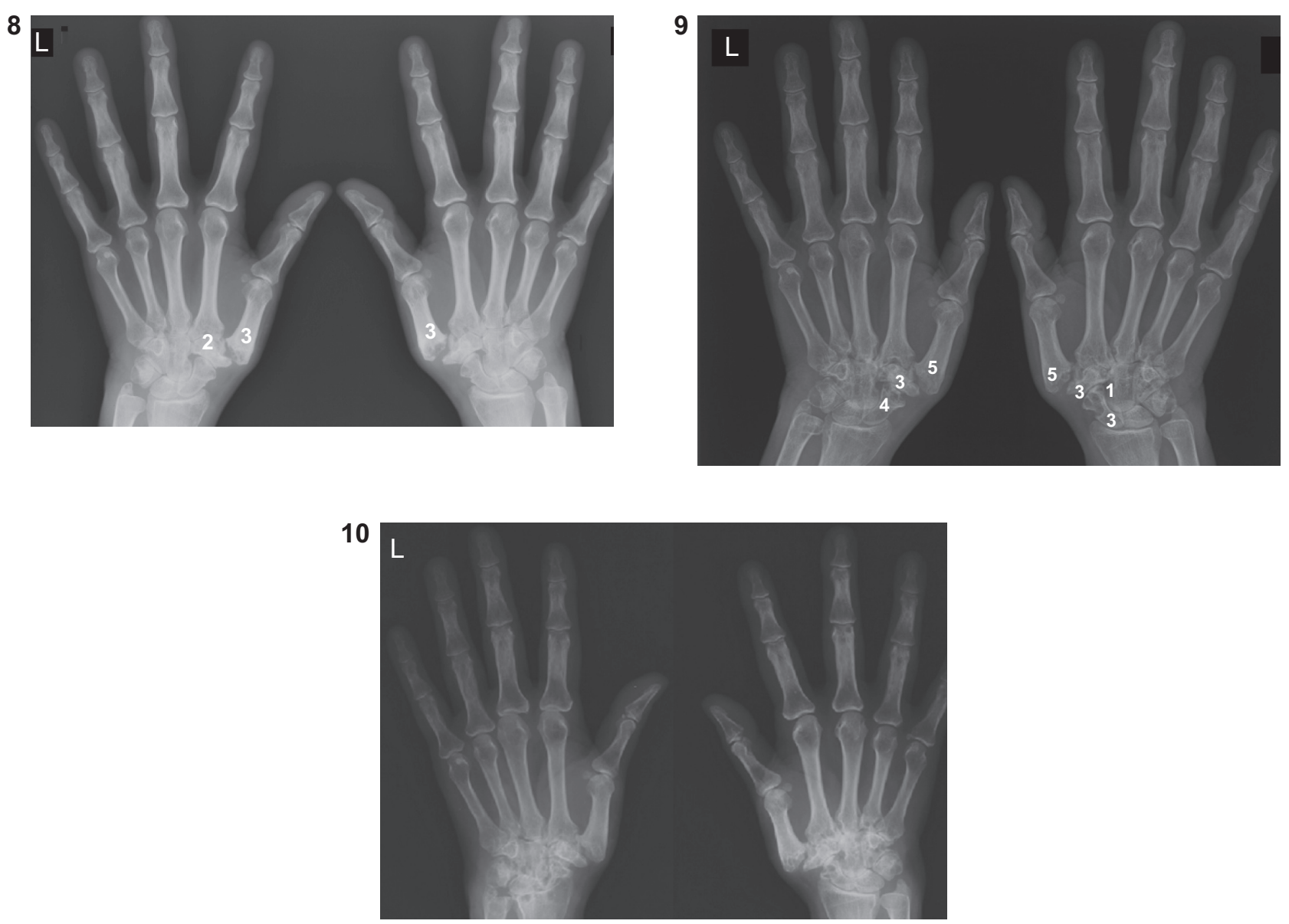

Figures 8-10 Example of erosion progression on radiographs of the hands obtained at 6-month intervals. The Sharp/van der Heijde erosion scores are shown in white. Figure 8, at inclusion: on the left, erosions were scored 3 at the first carpometacarpal joint and 2 at the trapezoid bone, and on the right erosions were scored 3 at the first carpometacarpal joint. Figure 9, 6 months later: on the left, erosions were scored 5 at the first carpometacarpal joint, 3 at the trapezoid bone, and 4 at the scaphoid; on the right, corresponding scores were 5, 3, and 4, respectively. Figure 10, at 12 months: severe damage to the carpal joints.

107 days), $22 \%$ of the 813 patients had erosions at baseline. Although some patients with early RA may experience a spontaneous remission or only mild disease progression, most require treatment.

\section{Analyzing radiographic progression scores}

Although the efficacy of DMARDs in preventing structural joint damage is often assessed based on changes in mean or median TSS values, cumulative probability plots provide additional insight into the effects of drugs on radiographic progression. Cumulative probability plots indicate the percentage of patients with radiographic progression and the severity of progression in those patients. They show that a large majority of patients on biologics (chiefly TNF- $\alpha$ inhibitors) experience no radiographic progression. ${ }^{19}$ Cumulative probability plots also provide information about differences between biologics and methotrexate regarding effects on radiographic progression.
Radiographic progression is defined as the smallest score change that cannot be ascribed to measurement error, ie, 0.5 point for the TSS. It should be borne in mind that the smallest score change that is clinically relevant is considerably larger, ie, 5 points per year. A Sharp score increase of 5 points per year is taken to indicate rapid progression requiring intensive treatment (Figures 11-14).

\section{Repair of structural joint damage}

An early radiographic concept that is generating new interest in RA since the introduction of biologics is structural damage repair, manifesting as a decrease in radiographic scores. For example, in patients taking combined TNF- $\alpha$ inhibitor and methotrexate treatment, the TSS decreased by 0.5 point after 52 weeks versus baseline.$^{20} \mathrm{~A}$ recent analysis of the TEMPO trial of etanercept and methotrexate showed a statistically significant decrease in the mean erosion score change in the subgroup of joints with absent or improved swelling. ${ }^{21}$ In contrast, radiographic progression was seen in joints with persistent swelling. 
11

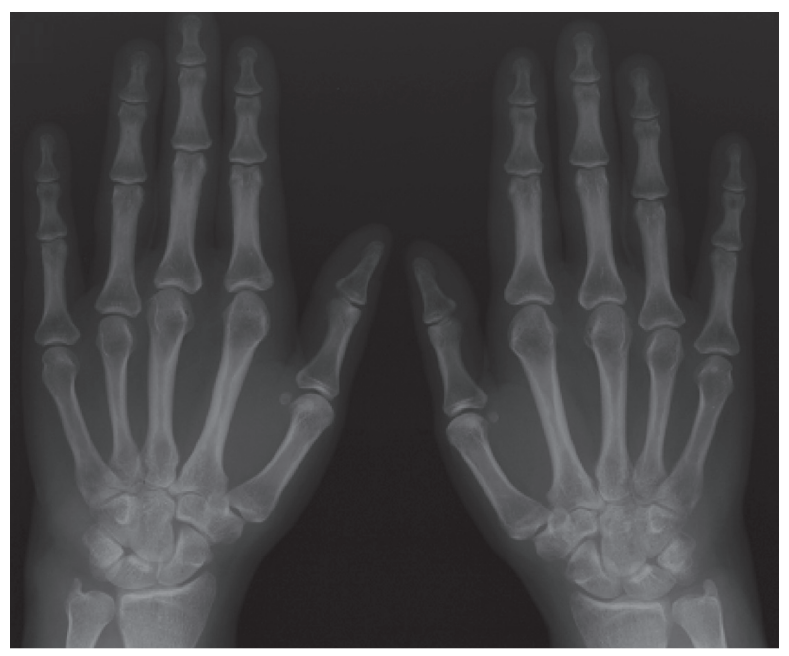

13

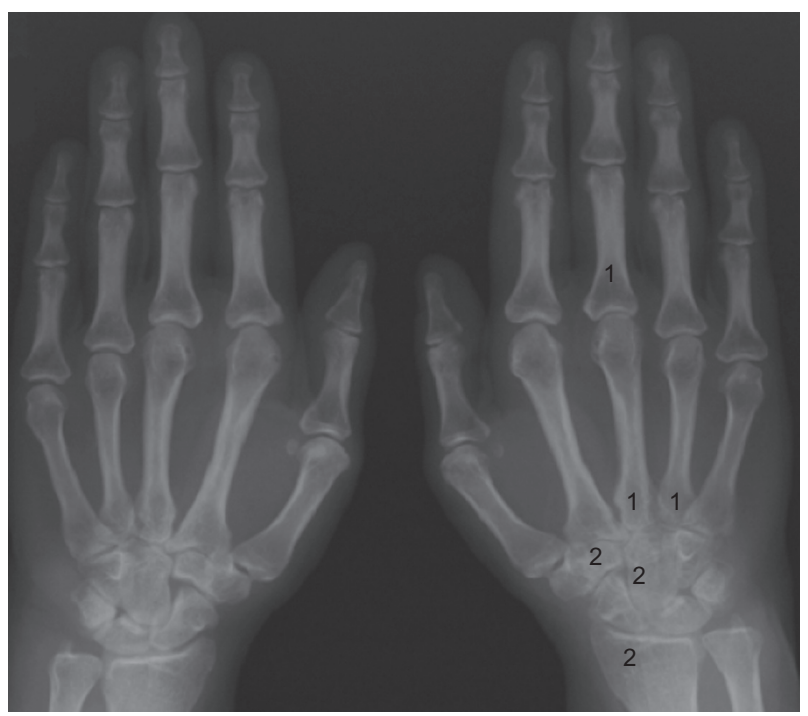

12

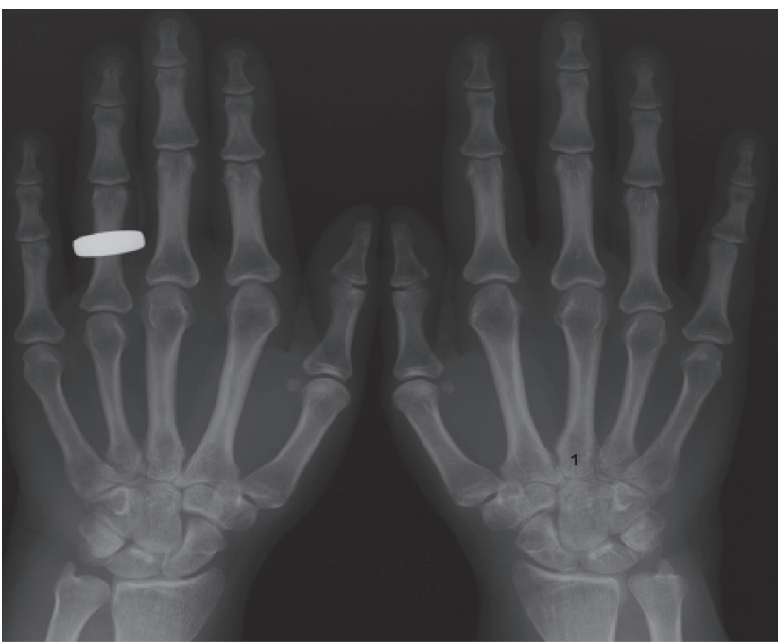

14

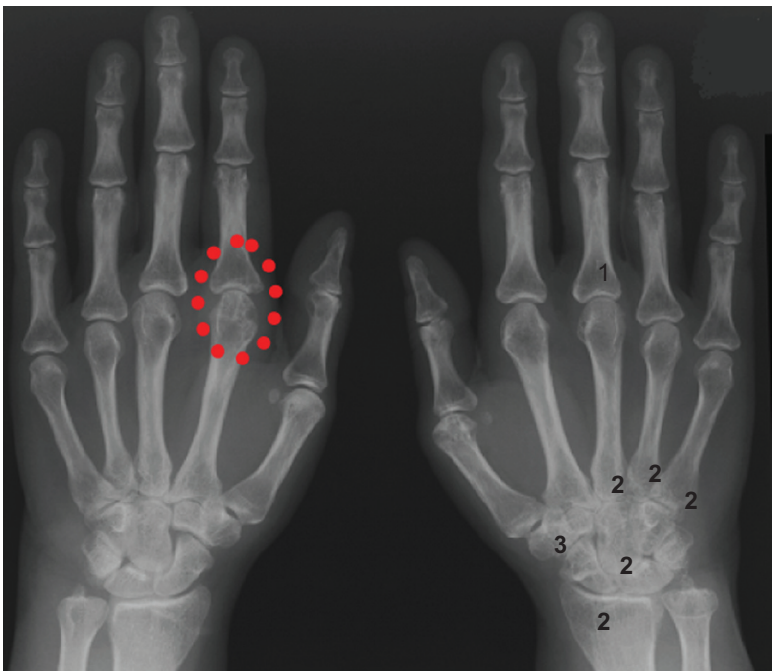

Figures I I-I4 Progression of joint space narrowing on radiographs obtained once a year and read using the Sharpe/van der Heijde score. The joint space narrowing (JSN) score is shown in black and the erosion score in white. At inclusion [II], the scores were 0 . At I year [I2], joint damage was visible on the right, with a JSN score of I and no erosions but with cysts in the scaphoid bone. A modification of the treatment was made. Radiographs obtained 6 months [13] and 2 years later, showed an increase of more than 5 points, indicating rapid progression. After 3 years [14], JSN was improved but the other abnormalities were unchanged and one new erosion was visible on a metacarpophalangeal joint, indicating a need for tighter disease control and reappraisal of the treatment strategy.

These data highlight the need for defining disease remission in RA. Several tools for defining a clinical remission have been developed, including cutpoints for the disease activity score on 28 joints (DAS28, 2.4), clinical disease activity index (CDAI, 2.8), and simple disease activity index (SDAI, 3.3). ${ }^{22}$ None of these scores takes radiographic data into account. The US Food and Drug Administration defines remission as complete absence of clinical manifestations and of radiographic progression for 6 months.

\section{Biological therapy in rheumatoid arthritis}

Biological agents have undergone considerable development in recent years. Several biologics have been approved for the treatment of RA, and they have changed the clinical and radiographic outcomes ${ }^{23}$ not only of patients with refractory RA, but also of those with recent-onset RA. Whether the available biologics differ in their ability to prevent radiographic progression is unknown. To date, no head-to-head studies of biologics in RA have been conducted.

\section{Biological therapies in established rheumatoid arthritis}

The first studies of biologics in RA were conducted in patients with established disease. Although the radiographic scores were already high at baseline, biologic therapies proved capable of decreasing radiographic progression. 


\section{Tumor necrosis factor alpha inhibitors}

Three TNF- $\alpha$ inhibitors are available and approved for RA patients (infliximab, etanercept, and adalimumab). TNF- $\alpha$ inhibitor therapy, particularly in combination with methotrexate, decreases both the proportion of patients with radiographic progression and the rate of change among patients who do progress, compared to methotrexate therapy alone. The percentage of patients with no radiographic progression is $75 \%$ to $85 \%$ with combined biologic and methotrexate therapy, compared to $50 \%$ with methotrexate alone. With methotrexate alone, scores increased by 2.3 to 6.1 , whereas the estimated score increase without treatment was 10.3 to 25.6. Importantly, combining TNF- $\alpha$ inhibitors with methotrexate further decreased the rate of joint damage progression (scores between -0.5 and 1.3). ${ }^{24,25}$ Prevention of radiographic progression seems comparable across TNF- $\alpha$ inhibitors. These studies also demonstrated that, compared to methotrexate alone, TNF- $\alpha$ inhibitors produced higher radiographic remission rates at every level of disease activity and response.

\section{Infliximab}

Infliximab substantially decreases radiographic disease progression in established RA. In the ATTRACT study, ${ }^{26}$ patients with established RA were randomized to receive infliximab or placebo, plus methotrexate in both groups. Infliximab substantially delayed joint destruction, even in patients who showed no improvement in clinical disease measures. Radiographic progression was considerably more severe with methotrexate plus placebo than with infliximab plus methotrexate, irrespective of the ACR response status (mean change in modified Sharp/van der Heijde score, 6.0 in ACR20 responders and 7.2 in ACR20 nonresponders in the methotrexate plus placebo-treated group, versus 0.1 in ACR20 responders and 1.2 in ACR20 nonresponders in the infliximab plus methotrexate group). Furthermore, among patients who exhibited no clinical response through week 54, those receiving infliximab plus methotrexate had a statistically significant decrease in radiographic progression by week 54 compared to the placebo group $(P<0.05$ to $P<0.001)$.

\section{Etanercept}

The efficacy of etanercept was established in the TEMPO study (Trial of Etanercept and Methotrexate with Radiographic Patient Outcomes), in which 686 patients with active RA were randomized to etanercept alone, methotrexate alone, or etanercept plus methotrexate..$^{24}$ Clinical and radiographic outcomes were evaluated at 52 weeks. The combination was better than methotrexate or etanercept alone in slowing radiographic joint damage (mean TSS, -0.54 [95\% CI, -1.00 to -0.07$]$ vs 2.80 [ 1.08 to 4.51$], P=0.0001$; and 0.52 [ -0.10 to 1.15$], P=0.0006$; respectively). Mean TSS differences were -3.34 [95\% CI, -4.86 to $-1.81, P<0.0001]$ between the combination and methotrexate alone $-27(-3.81$ to -0.74 , $P=0.047)$ between etanercept and methotrexate. An improvement in the radiographic score was also found in a recent longitudinal analysis of etanercept in early RA. ${ }^{27}$ Among patients receiving combination therapy, $78 \%$ of patients had no radiographic progression, compared with $68 \%$ of patients receiving etanercept alone, and $60 \%$ of those receiving methotrexate alone $(P<0.05)$. In a 52-week extension trial taking TEMPO to 4 years in all, almost $50 \%$ of RA patients in the combination therapy group achieved a remission (DAS $28 \leq 2.6$ ). In the combination group, the mean TSS change was smaller than in the single-drug groups and there was evidence of an arrest in radiographic progression. ${ }^{28}$

\section{Adalimumab}

The PREMIER study compared combined adalimumab and methotrexate therapy to either drug alone in 799 patients with early active RA who were naive to methotrexate. ${ }^{29}$ Adalimumab produced similar results to those seen with infliximab or etanercept, with slower joint progression in the treatment group. Co-primary endpoints at 1 year were the ACR50 response rate and the mean change from baseline in the modified TSS. Combination therapy was better than either drug alone for all study outcomes. Radiographic progression after 1 and 2 years with the combination (1.3 and 1.9 Sharp units, respectively) was significantly less marked $(P \leq 0.002)$ than with methotrexate alone (5.7 and 10.4 Sharp units) or adalimumab alone (3.0 and 5.5 Sharp units).

\section{Anti-CD 20 therapies}

Rituximab has been evaluated in patients with active RA who had failed to respond to TNF- $\alpha$ antagonist therapy and, based on the results, rituximab has been approved in this indication. The REFLEX study (Randomized Evaluation of Long-Term Efficacy of Rituximab in RA) showed that rituximab decreased radiographic progression compared to a placebo at 24 and 56 weeks. ${ }^{30}$ This study included 520 patients with active RA for at least 6 months and methotrexate therapy for at least 12 weeks. The primary efficacy endpoint was the ACR 20 response rate at 24 weeks. The Genant-modified Sharp radiographic score at 24 weeks was a secondary endpoint. The patients were randomized to rituximab or placebo, plus methotrexate in both groups. 
At 24 weeks, a trend toward less radiographic progression was noted in the rituximab plus methotrexate group. The total Genant-modified Sharp score at 24 weeks was $0.6 \pm 1.9$ in the rituximab plus methotrexate group and $1.2 \pm 3.3$ in the placebo plus methotrexate group $(P=0.169)$. The mean JNS score change from baseline to 24 weeks was significantly less in the patients receiving rituximab $(0.2 \pm 0.8)$ than in the patients receiving the placebo $(0.5 \pm 1.5)(P=0.016)$.

\section{Anti-IL-6 therapy}

The CHARISMA ${ }^{31}$ and RADIATE ${ }^{32}$ trials established the clinical efficacy and safety of tocilizumab combined with methotrexate in patients with RA refractory to TNF- $\alpha$ antagonist therapy. The SAMURAI ${ }^{33}$ trial comparing tocilizumab alone to synthetic DMARDs in 306 patients with active RA showed significantly less change in the TSS at week 52 versus baseline with tocilizumab (mean, 2.3; 95\% CI, 1.5 to 3.2) than with synthetic DMARDS (mean, 6.1; 95\% CI, 4.2 to $8 ; P<0.01$ ).

\section{Inhibition of co-stimulation}

Abatacept is a CTLA-4/Ig fusion protein approved for patients with RA refractory to TNF- $\alpha$ antagonists. Abatacept has been shown to slow radiographic progression over 52 weeks, albeit in more modest measure than TNF- $\alpha$ antagonists. The slower onset of action of abatacept may explain the smaller effect in preventing radiographic progression with abatacept than with methotrexate in early studies. The AIM study of patients with active RA despite methotrexate therapy showed that radiographic progression was slower with abatacept than with a placebo. ${ }^{34}$ The mean changes from baseline were 0.63 with abatacept versus 1.14 with placebo for the erosion score, 0.58 with abatacept versus 1.18 with placebo for the JSN score, and 1.21 with abatacept versus 2.32 with placebo for the TSS.

\section{Biological therapies in early rheumatoid arthritis}

Early synthetic DMARD treatment does not always prevent the development of structural joint damage. Randomized controlled trials have demonstrated that most of the biologics, when used in combination with methotrexate, can block radiographic progression. However, differences in terms of joint destruction are sometime very modest and require that experts define the 'acceptable rate of progression for one patient/year' (Figures 11-14).

\section{Infliximab}

In ASPIRE (Active controlled Study of Patients receiving Infliximab for the treatment of RA of Early onset), at every level of disease activity achieved at 14 weeks, the infliximab plus methotrexate combination decreased radiographic progression at 54 weeks compared with methotrexate plus placebo. ${ }^{35}$ In a post-hoc analysis of ASPIRE data, radiographs of the hands ( 870 patients) and feet ( 871 patients) were scored using the van der Heijde/Sharp method at baseline and at week 54. At baseline, in the placebo plus methotrexate group, erosions were seen in $8.5 \%$ of joints, JSN only in $4.4 \%$, both in $3.7 \%$, and neither in $83.4 \%$. These proportions were similar in the infliximab plus methotrexate group. At week 54, most joints in both groups had no development or progression of radiographic damage. The proportion of joints with damage at week 54 was superior in the placebo group than in the infliximab group. In this study, joints with erosions or JSN at baseline more often showed progression of the existing damage than the development of new damage.

\section{Etanercept}

In the Enbrel ERA (early RA) trial, absence of radiographic progression during the 12-month follow-up was significantly more common in the etanercept group than in the methotrexate group $(72 \%$ vs $60 \% ; P=0.007) .{ }^{27,36,37}$ In this study, 632 patients with early RA were assigned to twice-weekly subcutaneous etanercept (10 or $25 \mathrm{mg}$ ) or weekly oral methotrexate (mean, $19 \mathrm{mg}$ per week) for 12 months. The Sharp erosion and JSN scores were determined. Compared to patients who received methotrexate, patients who received etanercept had a faster rate of improvement. The mean erosion score increases were 0.30 in the group assigned to $25 \mathrm{mg}$ of etanercept and 0.68 in the methotrexate group $(P=0.001)$ during the first 6 months and 0.47 and $1.03(P=0.002)$ during the first 12 months. In conclusion, compared to methotrexate, etanercept acted more rapidly to alleviate the symptoms and slow the joint damage in patients with early active RA. However, although significant, the differences regarding radiographic progression were modest. This result further emphasizes the need for defining the acceptable rate of radiographic progression in recent-onset RA.

\section{Biologic therapies vs intensive synthetic DMARD treatment}

Intensive treatment to achieve tight disease control is now recognized as the best way to control radiographic progression in RA, based on the results of several randomized controlled trials. In the TICORA study, the intensive treatment group developed less radiographic damage than the control group, after 18 months. ${ }^{38}$ Randomized controlled trials of TNF- $\alpha$ antagonists in early RA 


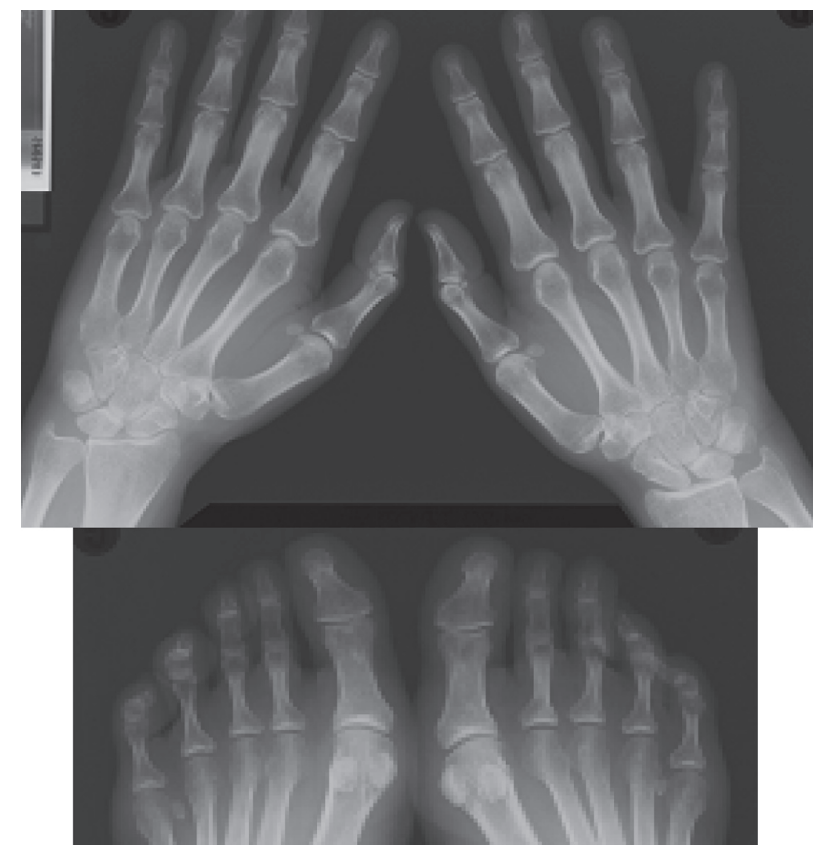

Inclusion

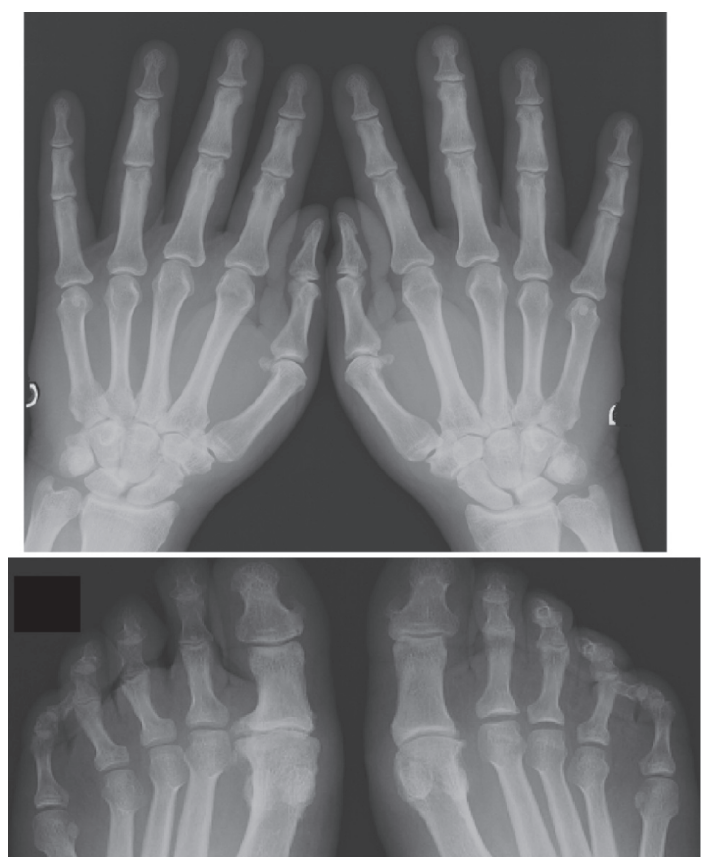

After 4 years

Figure 15 No radiographic progression over a 4-year period.

also support the efficacy of intensive treatment programs. They showed less radiographic progression with TNF- $\alpha$ antagonists, especially combined with methotrexate, compared to methotrexate alone. In the COMET study, among patients given TNF- $\alpha$ antagonist plus methotrexate therapy, $75 \%$ to $84 \%$ had no radiographic progression at week 52 compared to baseline. Studies have shown better response rates in patients given combinations of various synthetic DMARDs and either a TNF- $\alpha$ antagonist or brief high-dose corticosteroid therapy, compared to patients who were given TNF- $\alpha$ antagonists only if they failed to respond to several synthetic DMARDs used as monotherapy. Inflammation control was achieved earlier and the radiographic response was better with combination therapy started at disease onset than with the sequential use of various DMARDs as monotherapy.

In conclusion, although the outcome of RA is difficult to predict, most patients develop radiographic joint damage. Methotrexate is the anchor drug for the treatment of RA and can be used either alone or in combination with other synthetic DMARDs or with biologics to prevent joint damage. The available evidence indicates that most of the new biotherapies are effective in controlling the joint damage in most patients with RA (Figure 15). However, no head-to-head comparisons of biologics are available. In addition, further work is needed to better identify RA patients who will go on to experience rapid progressive joint damage. The development of a matrix model based on all predictors may help in this regard. ${ }^{39}$ The individual prediction model needs further evaluation. Until then, we must strive to improve disease control, in particular, by proving a clinical evaluation every 3 months and a radiographic evaluation every 6 months.

\section{Disclosure}

The authors report no conflicts of interest in this work.

\section{References}

1. Guillemin F, Saraux A, Guggenbuhl P, et al. Prevalence of rheumatoid arthritis in France: 2001. Ann Rheum Dis. 2005;64(10):1427-1430.

2. Klareskog L, Catrina AI, Paget S. Rheumatoid arthritis. Lancet. 2009;373(9664):659-672.

3. Haraoui B. Assessment and management of rheumatoid arthritis. J Rheumatol Suppl. 2009;82:2-10.

4. Wolfe F, Sharp JT. Radiographic outcome of recent-onset rheumatoid arthritis: a 19 years study of radiographic progression. Arthritis Rheum. 1998;41(9):1571-1582.

5. Hulsmans HM, Jacobs JW, van der Heijde DM, et al. The course of radiologic damage during the six years of rheumatoid arthritis. Arthritis Rheum. 2000;43(9):1927-1940.

6. Rubbert-Roth A, Finckh A. Treatment options in patients with rheumatoid arthritis failing initial TNF inhibitor therapy: a critical review. Arthritis Res Ther. 2009;11 Suppl 1:S1.

7. Devauchelle-Pensec V, Josseaume T, Samjee I, Dougados M, Combe B, Saraux A. Ability of oblique foot radiographs to detect erosions in early arthritis: results in the ESPOIR cohort. Arthritis Rheum. 2008; 59(12):1729-1734.

8. Baron G, Boutron I, Giraudeau B, Ravaud P. Reporting of radiographic methods in randomized controlled trials assessing structural outcomes in rheumatoid arthritis. Ann Rheum Dis. 2007;66(5):651-657. 
9. Boini S, Guillemin F. Radiographic scoring methods as outcome measures in rheumatoid arthritis: properties and advantages. Ann Rheum Dis. 2001;60(9):817-827.

10. van der Heijde DM. How to read radiographs according to the Sharp/ van der Heijde Method. J Rheumatol. 2000;27:261-263.

11. Sharp JT, Lidsky MD, Collins LC, Moreland J. Methods of scoring the progression of radiologic changes in rheumatoid arthritis. Correlation of radiologic, clinical and laboratory abnormalities. Arthritis Rheum. 1971;14(6):706-720.

12. van der Heijde DM. Joint erosions and patients with early rheumatoid arthritis. Br J Rheumatol. 1995;34 Suppl 2:74-78.

13. Genant HK, Jiang Y, Peterfy C, Lu Y, Redei J, Countryman PJ. Assessment of rheumatoid arthritis using a modified scoring method on digitized and original radiographs. Arthritis Rheum. 1998;41(9): $1583-1590$.

14. Drossaers-Bakker KW, Zwinderman AH, Vliet Vlieland TP, et al. Longterm outcome in rheumatoid arthritis: A simple algorithm of baseline parameters can predict radiographic damage, disability, and disease course at 12-year followup. Arthritis Rheum. 2002;47(4):383-390.

15. van der Heijde DM, Boonen A, Boers M, et al. Reading radiographs in chronological order, in pairs or as single films has important implications for the discriminative power of rheumatoid arthritis clinical trials. Rheumatology (Oxford). 1999;38(12):1213-1220.

16. Devauchelle-Pensec V, Berthelot JM, Jousse S, et al. Performance of hand radiographs in predicting the diagnosis in patients with early arthritis. J Rheumatol. 2006 33(8):1511-1515.

17. Guillemin F, Billot L, Boini S, Gerard N, Ødegaard S, KvienTK. Reproducibility and sensitivity to change of 5 methods for scoring hand radiographic damage in patients with rheumatoid arthritis. J Rheumatol. 2005;32(5):778-786.

18. Combe B, Benessiano J, Berenbaum F, et al. The ESPOIR cohort: A ten-year follow-up of early arthritis in France: Methodology and baseline characteristics of the 813 included patients. Joint Bone Spine. 2007;74(5):440-445.

19. Taylor PC, Feldmann M. Anti-TNF biologic agents: still the therapy of choice for rheumatoid arthritis. Nat Rev Rheumatol. 2009;5(10): $578-582$.

20. van der Heijde D, Klareskog L, Rodriguez-Valverde V, et al. Comparison of etanercept and methotrexate alone and combined in the treatment of rheumatoid arthritis: two year clinical and radiographic results from the TEMPO study, a double blind, randomized trial. Arthritis Rheum. 2006;54(4):1063-1074.

21. Lukas C, van der Heijde D, Fatenejad S, Landewé R. Repair of erosions occurs almost exclusively in damaged joints without swelling. Ann Rheum Dis. 2010;69(5):851-855.

22. Aletaha D, Landewe R, Karonitsch T, et al. Reporting disease activity in clinical trials of patients with rheumatoid arthritis: EULAR/ACR collaborative recommendations. Ann Rheum Dis. 2008;67(10): 1360-1364.

23. Smolen JS, Aletaha D, Koeller M, Weisman MH, Emery P. New therapies for treatment of rheumatoid arthritis. Lancet. 2007;370(9602): 1861-1874.

24. Klareskog L, van der Heijde D, de Jager JP, et al. Therapeutic effect of the combination of etanercept and methotrexate compared with each treatment alone in patients with rheumatoid arthritis: double-blind randomized controlled trial. Lancet. 2004;363(9410):675-681.

25. Smolen JS, van Der Heijde DM, St Clair EW, et al. Predictors of joint damage in patients with early rheumatoid arthritis treated with high-dose methotrexate with or without concomitant infliximab: results from the ASPIRE trial. Arthritis Rheum. 2006;54(3):702-710.

Reports in Medical Imaging

\section{Publish your work in this journal}

Reports in Medical Imaging is an international, peer-reviewed, open access journal publishing original research, reports, reviews and commentaries on all areas of medical imaging. The manuscript management system is completely online and includes a very quick and fair peer-review system, which is all easy to use.

Submit your manuscript here: http://www.dovepress.com/reports-in-medical-imaging-journal
26. Smolen JS, Han C, Bala M, et al. Evidence of radiographic benefit of treatment with infliximab plus methotrexate in rheumatoid arthritis patients who had no clinical improvement: a detailed subanalysis of data from the anti-tumor necrosis factor trial in rheumatoid arthritis with concomitant therapy study. Arthritis Rheum. 2005;52(4):1020-1030.

27. Genovese MC, Bathon JM, Martin RW, et al. Etanercept versus methotrexate in patients with early rheumatoid arthritis: two-year radiographic and clinical outcomes. Arthritis Rheum. 2002;46(6): $1443-1450$.

28. van der Heijde D, Landewé R, van Vollenhoven R, Fatenejad S, Klareskog $L$. Level of radiographic damage and radiographic progression are determinants of physical function: a longitudinal analysis of the TEMPO trial. Ann Rheum Dis. 2008;67(9):1267-1270.

29. Breedveld FC, Weisman MH, Kavanaugh AF, et al. The PREMIER study: a multicenter, randomized, double-blind clinical trial of combination therapy with adalimumab plus methotrexate versus methotrexate alone or adalimumab alone in patients with early, aggressive rheumatoid arthritis who had not had previous methotrexate treatment. Arthritis Rheum. 2006;54(1):26-37.

30. Cohen SB, Emery P, Greenwald MW, et al. Rituximab for rheumatoid arthritis refractory to anti-tumor necrosis factor therapy: results of a multicenter, randomized, double-blind, placebo-controlled, phase III trial evaluating primary efficacy and safety at twenty-four weeks. Arthritis Rheum. 2006;54(9):2793-2806.

31. Maini RN, Taylor PC, Szechinski J, et al. Double-blind randomized controlled clinical trial of the interleukin- 6 receptor antagonist, tocilizumab, in European patients with rheumatoid arthritis who had an incomplete response to methotrexate. Arthritis Rheum. 2006;54(9): 2817-2829.

32. Emery P, Keystone E, Tony HP, et al. IL-6 receptor inhibition with tocilizumab improves treatment outcomes in patients with rheumatoid arthritis refractory to anti-tumour necrosis factor biologicals: results from a 24-week multicentre randomised placebo-controlled trial. Ann Rheum Dis. 2008;67(11):1516-1523.

33. Nishimoto N, Hashimoto J, Miyasaka N, et al. Study of active controlled monotherapy used for rheumatoid arthritis, an IL-6 inhibitor (SAMURAI): evidence of clinical and radiographic benefit from an $\mathrm{x}$ ray reader-blinded randomised controlled trial of tocilizumab. Ann Rheum Dis. 2007;66(9):1162-1167.

34. Kremer JM, Genant HK, Moreland LW, et al. Effects of abatacept in patients with methotrexate-resistant active rheumatoid arthritis: a randomized trial. Ann Intern Med. 2006;144(12):865-876.

35. Smolen JS, van der Heijde DM, Aletaha D, et al. Progression of radiographic joint damage in rheumatoid arthritis: independence of erosions and joint space narrowing. Ann Rheum Dis. 2009;68(10): 1535-1540.

36. Bathon JM, Martin RW, Fleischmann RM, et al. A comparison of etanercept and methotrexate in patients with early rheumatoid arthritis. $N$ Engl J Med. 2000;343(22):1586-1593.

37. Genovese MC, Bathon JM, Fleischmann RM, et al. Longterm safety, efficacy, and radiographic outcome with etanercept treatment in patients with early rheumatoid arthritis. J Rheumatol. 2005;32(7):1232-1242.

38. Grigor C, Capell H, Stirling A, et al. Effect of the treatment strategy of tight control for rheumatoid arthritis (the TICORA study): a single blind randomised controlled study. Lancet. 2004;364(9430):263-269.

39. Vastesaeger N, Xu S, Aletaha D, St Clair EW, Smolen JS. A pilot risk model for the prediction of rapid radiographic progression in rheumatoid arthritis. Rheumatology. 2009;48(9):1114-1121.

\section{Dovepress}

Visit http://www.dovepress.com/testimonials.php to read real quotes from published authors. 